\title{
The Daily Market for Funds in Europe: What Has Changed with the EMU?*
}

\author{
Gabriel Pérez Quirós ${ }^{\dagger}$ \\ Banco de España
}

\author{
Hugo Rodríguez Mendizábal ${ }^{\ddagger}$ \\ Universitat Autònoma de Barcelona
}

February 3, 2003

\begin{abstract}
This paper presents evidence that the existence of deposit and lending facilities combined with an averaging provision for the reserve requirement are powerful tools to stabilize the overnight rate. We reach this conclusion by comparing the behavior of this rate in Germany before and after the start of the EMU. The analysis of the German experience is useful because it allows to isolate the effects on the overnight rate of these particular instruments of monetary policy. To show that this outcome is a general conclusion and not a particular result of the German market, we develop a theoretical model of reserve management which is able to reproduce our empirical findings.

Keywords: Overnight Rates; Reserve Demand; Martingale Hypothesis;

JEL codes: E44, E52;
\end{abstract}

\footnotetext{
${ }^{*}$ We thank Ulrich Bindseil, Doris Decker, María Encio, José L. Escrivá, Vitor Gaspar, Philipp Hartmann, Michele Manna, Gabriel Quirós, the editor, two anonimous referees and specially Spence Hilton for helpful discussions and suggestions. The views expressed in the paper are those of the authors and do not necessarily reflect the views of the Bank of Spain or the European System of Central Banks. Rodríguez Mendizábal aknowledges financial support from the Spanish Ministry of Science and Technology through grant SEC2000-0684.

†Servicio de Estudios, Banco de España, Alcala 50. 28014 Madrid. Spain. E-mail: gabriel.perez@bde.es.

$\ddagger$ Department of Economics and Economic History. Edifici B. Universitat Autònoma de Barcelona. 08193 Bellaterra Barcelona, Spain. E-mail: hugo.rodriguez@uab.es.
} 


\section{Introduction}

The daily market for funds is the generic denomination for the market where financial institutions trade overnight unsecured loans of their deposits at the central bank. The interest rate set in this market (henceforth called, indistinctly, the overnight rate, or the daily rate) plays a key role for the conduct of monetary policy. This is because the operating procedures of central banks are designed to affect the supply and demand of reserves among financial institutions.

Which are the determinants of the overnight rate? Central banks try to control it by using the instruments in their hands, namely, open market operations, reserve requirements and standing facilities. Control means an attempt to keep the daily rate around an "official rate" which in some countries is a "target rate" and in others is just the rate of the open market operations. One consequence of this control is that daily rates closely follow the rates determined by central banks. However, since this control is not perfect, the spread between market rates and official rates is usually different from zero. This difference gives an indication of the part of the daily rate which is driven by market forces. Figure 1 presents an example of such a series. It shows the spread between the overnight rate and the rate of the main refinancing operations (MRO) in Germany for the period covering from September 2nd 1996 to January 23rd 2003. The dashed vertical lines represent the end of reserve maintenance periods. The most remarkable feature of this series is the outstanding differences in its behavior before and after January 1999. Before this date, the last days of the reserve maintenance periods were characterized by significant peaks in the spread, which disappeared once the EMU was in place. ${ }^{1}$

This paper deals with characterizing and explaining the change in the behavior of the mean process for the overnight rate in Germany. We believe that this discussion goes beyond analyzing a particular historical episode in a particular country. Instead, we argue that it helps us understand the role of fundamental forces determining the time series properties of this rate in any economy. What makes the German experience with the EMU a singular one is that it represents the closest we can get to a controlled experiment in Macroeconomics. We show that this experiment allows us to trace the effect on the daily rate of changes in the operating procedures of central banks.

We develop a model to reproduce our empirical findings. This means explaining not only the properties of the overnight rate in the pre- and post-EMU periods but also the sudden change in its behavior. The explanation is based on modeling the degree of substitutability of funds within the reserve maintenance period. It is commonly said that if banks are risk neutral and there are no market frictions, funds should be perfect substitutes among days of the same reserve maintenance period. This would imply that banks would arbitrage away any expected differences between the current and future cost of funds. In other words, overnight rates should follow a martingale.

\footnotetext{
${ }^{1}$ In this paper, when we use the term EMU or monetary union, we refer to the Stage III of EMU.
} 
The main contribution of the paper is to demonstrate that this conclusion is not true even in an environment where agents are risk neutral and there are no impediments to trade. We reach this outcome by formalizing the instrumentation of monetary policy and by showing how it has different effects on the opportunity cost of funds for different days in the same reserve maintenance period. The corollary of this result is that banks do not see funds on different days as perfect substitutes. In addition, it allows us to rationalize the changes in the behavior of the overnight rate by comparing the implementation of monetary policy before and after the EMU.

It is important to notice that our theory is not in competition with other explanations of the lack of substitutability of funds within the reserve maintenance period which are based on market frictions or risk averse behavior. Our point is that we do not need those ingredients to understand deviations from the martingale hypothesis. In this sense, we just explore another dimension of the problem that we think is quantitatively important but that has not at all been explored in the literature. Additionally we will argue that, taken by itself, it offers a better explanation of the likely effects that the EMU has had on the behavior of the overnight rate.

The line of the argument is developed as follows. Section 2 characterizes the time series properties of the spread between the daily rate and the rate of the main refinancing operations in Germany. We show that there is a structural break in this series associated with the EMU. In particular, before January 1999, we find a significant increase in the conditional mean of the daily rate at the end of the reserve maintenance period. This effect is lost after 1999. This section also discusses why we concentrate in the German case and provides possible explanations for our empirical findings. It turns out that existing theories of the determination of the overnight rate within the reserve maintenance period have difficulties in explaining this pattern. Section 3 associates these results with the changes in the implementation of monetary policy observed in Germany since the beginning of 1999. We develop a model of competitive, risk-neutral banks which is able to reproduce the features we find in the data. In this sense, the model generates a sequence for the overnight rate with peaks at the end of the maintenance period. We show that this feature of the daily rate crucially depends on the official rates of the central bank. Finally, section 4 concludes.

\section{The Empirical Analysis}

\subsection{Data and Descriptive Statistics}

The sample consists of daily observations covering the period from September 1, 1996 until January 23, 2003. For the period before January 1999, we use the spread between the overnight rate determined in the German money market and the rate of the main refinancing operations of the Bundesbank. We have 582 observations for the first subsample. ${ }^{2}$ After January 1, 1999, the series studied is

\footnotetext{
${ }^{2}$ It is after September 1996 that the Bundesbank had an explicit official rate.
} 
the difference between the Eonia and the rate of the main refinancing operations of the ECB. ${ }^{3}$ The Eonia is a volume weighted average of all overnight unsecured lending transactions initiated within the euro area by a particular panel of banks. The contributors to Eonia are the banks with the highest volume of business in the euro zone money markets. ${ }^{4}$ This series is indistinguishable from the corresponding interest rate in the German money market for that period. ${ }^{5}$ We have 1037 observations of this variable from January 1, 1999 to January 23rd, 2003. Our linked series, therefore, includes a total of 1619 observations and describes the part of the overnight rate determined by market forces. It is plotted in Figure 1.

Just by looking at Figure 1, we can observe one characteristic that makes this series "special". Days close to the end of the maintenance period, depicted in the graph by vertical lines, usually present higher uncertainty. Most of the "atypical" observations (in a linear sense) are associated with these days. For example, if we construct a two standard error band around the "official rate", we can observe that most of the times in which this variable is out of that interval, happen during the last days of the maintenance periods. In particular, before January $1999, i_{t}$ is 28 times outside this band, 27 of which are on the last two days of the period. After the EMU, this ratio is just 29 to 69 . Additionally, as mentioned in the introduction, the series seems to present a structural break because the peaks associated with the end of the maintenance period before the EMU are no longer present in the series after the EMU. In order to assess the significativity of these peaks we use the sign test. With this nonparametric test, we check if the probability of finishing the maintenance period above or below the rate of the main refinancing operation is just 0.5. In the case of Germany before the EMU we clearly reject the null with a p-value of 0.000 . After the EMU we accept the null with a p-value of 0.32 . We also test no-parametrically the differences between the spread on the last day of the maintenance period before and after the EMU. We use the Mann-Whitney test to test the null hypothesis that the central locations of the two distributions are the same. We can reject the null with a p-value of 0.000 . These results are a clear indication that something is different before and after the EMU.

Another way of looking at the data is shown in Figure 2. This figure presents the average spread for each day of the maintenance period. The horizontal axis represents the number of days left until the beginning of the next maintenance period. So, the number 1 refers to the last day of the period, number 2 to the previous day, and so on. As we can observe the main difference between the subsamples before and after the EMU is that the high, significant peak that

\footnotetext{
${ }^{3}$ For the period January 1999 to January 2003 we use the Euro-area rates (EONIA). The correlation between German rates and Euro-Area rates is 0.99. Additionally, after June 28, 2000, the series is the difference between the Eonia and the minimum rate for the variable rate tender operations.

${ }^{4}$ In particular, these are 47 banks from EMU countries; 4 banks from non-EMU European countries; and 6 large international banks from non-EU countries but with important euro area operations. For more information on this rate, see the European Banking Federation's internet page for the Euribor at www.euribor.org.

${ }^{5}$ The correlation between German rates and euro-area rates is 0.99 .
} 
characterizes the behavior of the overnight rate before January 1999 is no longer present after that date.

The purpose of this paper is to give a credible explanation of what may explain this phenomena. Therefore, the econometric specification that we propose does not pretend to capture all the characteristics and variables that might explain the behavior of the overnight rate as the comprehensive models of Wurtz [15], or Bindseil and Seitz [4], but just to test empirically with the type of parametric models used in the literature how significant the break is. ${ }^{6}$

\subsection{Econometric Specification}

In order to test formally how significant this break is, we encompass the end of the maintenance period effect and the conditional heteroskedasticity typical in financial time series by proposing the following econometric specification:

$$
i_{t}=i_{t-1}+\beta^{\prime} X_{t}+h_{t} \epsilon_{t}
$$

with

$$
\begin{aligned}
\ln \left(h_{t}\right)= & \lambda^{\prime} \mathbf{V}_{t}+\sum_{j=1}^{4}\left[\delta_{j 1}\left(\ln \left(h_{t-j}\right)-\lambda^{\prime} \mathbf{V}_{t-j}\right)+\delta_{j 2} \frac{\epsilon_{t-j}}{\sqrt{h_{t-j}}}\right. \\
& \left.+\delta_{j 3}\left(\frac{\left|\epsilon_{t-j}\right|}{\sqrt{h_{t-j}}}-\sqrt{\frac{2}{\pi}}\right)\right]
\end{aligned}
$$

where $i_{t}$ is the overnight rate, $X_{t}$ collects a set of explanatory dummies that potentially could affect the mean and $V_{t}$ includes the ones that affect the variance. $^{7}$ The functional form of the variance is derived from the specification proposed by Nelson [12] and used in Hamilton [10]. This specification captures an EGARCH type of persistence but allowing for different effects of positive and negative shocks. It also controls for the effect of changing the unconditional variance from the transmission of the conditional variance in day $t-j$ to

\footnotetext{
${ }^{6}$ All the papers that present a full characterization of the behavior of the overnight rate only model the period after the EMU. These papers pretend to capture very specific phenomea of the data as the effect of liquidity conditions (Bindseil and Seitz [4]), the effect of meetings (Gaspar et al. [9]), the intraday patterns of rates (Hartmann et al. [11]) or everything at the same time as in Wurtz [15]. These specific facts are away of our main focus of interest, which is just to show that there exist statistical differences in the unconditional behavior of rates before and after the EMU. Additionally, a full model of the behavior of rates would need a huge set of information not available for the period before the EMU.

${ }^{7}$ In the econometric specification we use the overnight rate instead of the spread. This is because we construct a model in first differences and, therefore, the level of the rate is not an issue. The use of the spread would generate an unnecessary noise in the estimation since markets participants usually discount changes in the official rates at the beginning of the reserve maintenance period while they usually occur within the period (Gaspar et al. [9]). All the noise associated with expected changes in the target rate are captured with beggining of maintenance period dummies.
} 
day $t$ [represented by the term $\left.\ln \left(h_{t-j}\right)-\lambda^{\prime} \mathbf{V}_{t-j}\right]$. For the distribution of the error term, we use the mixture of normals proposed in Hamilton [10], because the fat tails and the excess of kurtosis made inappropriate the use of the normal distribution. Therefore, the density function of $\epsilon_{t}$ is:

$$
f\left(\epsilon_{t}\right)=p\left(2 \pi \sigma_{1}^{2}\right)^{-1 / 2} \exp \left(\frac{-\epsilon_{t}^{2}}{2 \sigma_{1}^{2}}\right)+(1-p)\left(2 \pi \sigma_{2}^{2}\right)^{-1 / 2} \exp \left(\frac{-\epsilon_{t}^{2}}{2 \sigma_{2}^{2}}\right) .
$$

As in Hamilton [10], we use the normalization, $\sigma_{1}^{2}=1$ which implies that $E\left(\epsilon_{t}^{2}\right)$ is $E\left(\epsilon_{t}^{2}\right)=p \sigma_{1}^{2}+(1-p) \sigma_{2}^{2}$ instead of being equal to one.

There is no consensus in the literature on how many days should be relevant to capture the end of the maintenance period effect. For example, Prati et al. [13] finds only the previous to last day significant while Wurtz [15] tries to explain the end of the maintenance period effect by using different dummies for different days. However, as suggested by our theoretical model, it is after the last main refinancing operation when the liquidity effect plays a role and when the end of the maintenance period constraint may have an impact. ${ }^{8}$ With this fact in mind, the sets $X_{t}$ and $V_{t}$ are composed of the variables included in Tables 1 and 2 .

Table 1

Variables in the Mean Equation $\left(\operatorname{set} X_{t}\right.$ )

\begin{tabular}{|c|c|}
\hline Variable & Meaning \\
\hline$X_{1 t}$ & $t$ occurs before January 1,1999 \\
\hline$X_{2 t}$ & $t$ occurs after January 1, 1999 \\
\hline$X_{3 t}$ & $\begin{array}{l}t \text { occurs before January } 1,1999 \text { and is a day after the } \\
\text { last MRO of the reserve maintenance period }\end{array}$ \\
\hline$X_{4 t}$ & $\begin{array}{l}t \text { occurs after January } 1,1999 \text { and is a day after the } \\
\text { last MRO of the reserve maintenance period }\end{array}$ \\
\hline$X_{5 t}$ & $\begin{array}{l}t \text { occurs before January } 1,1999 \text { and is the first } \\
\text { day of the reserve maintenance period }\end{array}$ \\
\hline$X_{6 t}$ & $\begin{array}{l}t \text { occurs after January } 1,1999 \text { and is the first day } \\
\text { of the reserve maintenance period }\end{array}$ \\
\hline
\end{tabular}

Table 2

Variables in the Variance Equation $\left(\right.$ set $V_{t}$ )

\begin{tabular}{cl}
\hline Variable & Meaning \\
\hline$V_{1 t}$ & $t$ occurs before January 1, 1999 \\
$V_{2 t}$ & $t$ occurs after January 1, 1999 \\
$V_{3 t}$ & $X_{3 t}+X_{5 t}$ \\
$V_{4 t}$ & $X_{4 t}+X_{6 t}$ \\
$V_{5 t}$ & end of the year dummy \\
$V_{6 t}$ & Friday effect \\
$V_{7 t}$ & end of the month effect after EMU \\
\hline
\end{tabular}

${ }^{8}$ Wurtz [15] and Angelini and Bisagni [1] share this view. 
This specification is the most parsimonious representation that we have found after trying different ones. Among the additional representations that we have estimated we have tried to separate the end of the maintenance period effect dummying for each day of week as in Wurtz [15]. However,separating the end of the maintenance period effect in too many variables makes insignificant most of them because of the small number of observations. ${ }^{9}$

One additional specification that deserve special attention was the one that included the end of the month effect in the mean after the EMU. The purpose of this specification was to test empirically the "window dressing effect" that some authors as Wurtz [15] point out as being important in explaining the change in behavior of the rates before and after the EMU The argument behind is that banks demand more reserve at the end of the month for accounting reasons. If this is true, the change of the end of the maintenance period from the end of the month to the 23rd, could explain why the end of the maintenance period does not present any more a significant increase in demand. If this argument is right, a significant increase in demand should be seen at the end of the month. However, we accept the null of non-significativity of the end of the month coefficient with a p-value of 0.20 .

Finally, one more caveat requires an additional comment. The theoretical model and the proposed econometric specification suggest that, given the weekly frequency of main refinancing operations, maintenance periods with more days after the last main refinancing operation should present proportionally larger increases in rates. ${ }^{10}$ Therefore, the subsequent decrease in rates the first day of the next maintenance period should also be proportional of the number of days past after the last main refinancing operation. We capture that effect by allowing the dummies that capture the beginning of the maintenance period effect $\left(X_{5 t}\right.$ and $\left.X_{6, t}\right)$ to take values from 1 to 5 as a function of the day of the week. For example if the beginning of the maintenance period is a Thursday, this would imply that the last day of the maintenance period was a Wednesday and the last main refinancing operation was in the morning of that Wednesday leaving only one day for the end of the maintenance period effect and giving a value of 1 for the beginning of the maintenance period dummy. If it was a Friday it would give a value of 2 and so on. This specification allows us to easily test if the changes at the end of the maintenance period are compensated away with the corresponding increase or decrease at the beginning of the next period.

\subsection{Results}

Tables 3 and 4 show the estimation results of (1) and (2).

\footnotetext{
${ }^{9}$ It is of particular interest the "Wednesday effect" where there is no increase of rates at the end of the maintenance period when the last MRO is in a Wednesday. This is somehow captured in our specification because we have only one day of increase rates on those maintenance period. However, testing this hypothesis separately for different days of the week is inappropriate. This is because the reduction in significativity due to the small number of maintenance period that finnish on each day of the week. This number is aproximately 6 for each day after the EMU (18 for Fridays) and less that 4 (12 for Fridays) before the EMU.

${ }^{10}$ The "Wednesday effect" is just one example of this phenomena.
} 
Table 3

Estimations in the Mean Equation

\begin{tabular}{ccc}
\hline Parameter & Estimate & Std. deviation \\
\hline$\beta_{1}$ & -0.002 & 0.0004 \\
$\beta_{2}$ & -0.001 & 0.0003 \\
$\beta_{3}$ & 0.072 & 0.021 \\
$\beta_{4}$ & -0.005 & 0.008 \\
$\beta_{5}$ & -0.133 & 0.009 \\
$\beta_{6}$ & 0.0001 & 0.001 \\
\hline
\end{tabular}

Table 4

Estimations in the Variance Equation

\begin{tabular}{ccc}
\hline Parameter & Estimate & Std. deviation \\
\hline$\lambda_{1}$ & -11.686 & 0.637 \\
$\lambda_{2}$ & -12.318 & 0.665 \\
$\lambda_{3}$ & 5.181 & 0.205 \\
$\lambda_{4}$ & 4.921 & 0.128 \\
$\lambda_{5}$ & 2.799 & 0.388 \\
$\lambda_{6}$ & 0.300 & 0.061 \\
$\lambda_{7}$ & 3.824 & 0.188 \\
\hline$\delta_{11}$ & 0.325 & 0.028 \\
$\delta_{21}$ & 0.015 & 0.005 \\
$\delta_{31}$ & 0.223 & 0.015 \\
$\delta_{41}$ & 0.109 & 0.020 \\
$\delta_{12}$ & 0.197 & 0.017 \\
$\delta_{13}$ & 0.043 & 0.025 \\
\hline$p$ & 0.371 & 0.017 \\
$\sigma_{1}$ & 1.000 & - \\
$\sigma_{2}$ & 6.005 & 0.192 \\
\hline
\end{tabular}

As Table 3 shows, the behavior of the overnight rate changes after January 1999. Before the EMU, the positive and significant value of $\beta_{3}$ implies that there is an increase of rates at the end of the maintenance period, of around 7 basis points per day after the last MRO. This increase is compensated with an associated negative variation at the beginning as measured by the parameter $\beta_{5}$. Remember that $\beta_{5}$ represents the dummy that takes values from one to five as a function of the number of days between the last MRO and the end of the reserve maintenance period. Interestingly, the increase of the spread on the last days of the maintenance period is very similar to the decrease at the beginning of the next maintenance period. This means that the first day of the period washes out any changes occurred around the previous settlement day. Statistically, we can not reject the hypothesis that $\beta_{3}=-\beta_{5}$ (p-value of 0.08).

However, after the EMU, none of the variables that capture end or beginning of the maintenance period effect is significant. The overnight rate follows closely the martingale hypothesis and tests of the non-significativity of the parameters 
$\beta_{2}$ and $\beta_{4}$ clearly accept the null that these are 0 . Additionally, contrary to the findings for the US case (Hamilton [10]), there is no significant effect of variables such as holidays or end-of-the week on the mean equation for both samples. This is probably due to the longer maintenance period in Europe.

With respect to the variance equation, the results show a similar pattern before and after the EMU, and we can accept the hypothesis that $\lambda_{1}=\lambda_{2}$ and $\lambda_{3}=\lambda_{4}$.

To sum up, according to the econometric results, we can conclude that something has happen to the mean of the overnight rate before and after the EMU. The rest of the paper tries to model what can explain this change of behavior.

\subsection{Discussion of our Empirical Results}

In this section we explain why we concentrate in the German experience with the EMU and discuss possible explanations for our empirical findings. First of all, the EMU seems a natural experiment to analyze. At least in principle, it is possible to identify all the institutional changes that this historical episode generated in the money markets of the Euro area. One of the main modifications in these markets has to do with the conduct of monetary policy. In this respect, most of the countries that initially entered the monetary union changed the instruments of their central banks so much that it is difficult to use their experience to learn anything about the determination of the overnight rate. Germany is the country participating in the EMU in which the operational framework has changed the least with the EMU. ${ }^{11}$ This means that we have to justify our empirical results by searching within a limited set of possible answers. In this sense, Germany provides an interesting case to study and, as it will be clearer in the next section, by doing this exercise we learn some important lessons that should be applicable to any country.

What has been different in German money markets since January 1999? The first thing that comes to our minds is the increase in the number of participants. With the EMU, potentially any bank in the Euro area can have access to the German market to obtain liquidity. One way this fat can explain our observations for the daily rate is by assuming that before January 1999 some bank had market power to control rates within the reserve maintenance period selling them cheap at the beginning and expensive at the end. This power disappeared with the enlargement of the market. A related issue has to do with the official supply of reserves. It may be possible that differences in the behavior of the Bundesbank and the ECB could also explain the observed pattern of the overnight rate. It has been recognized that the Bundesbank tended to be harder on the market on the last day of maintenance periods. The reason was that, by maintaining the market shorter they avoided the possibility of rates dropping to zero on those days. This has not been the case with the ECB. However, the main problem when using these interpretations at face value is that they do not

\footnotetext{
${ }^{11}$ See Escrivá and Fagan [7] for a description of the operating procedures of central banks in the Euro area before the EMU.
} 
provide an explanation as of why financial institutions did not take advantage of this situation. If German banks knew that it was systematically harder to get reserves at the end of the reserve maintenance periods, why did they keep demanding reserves on those days?

This discussion brings us to the crux of the matter. One of the central findings of the previous section is that we can reject the martingale hypothesis for the overnight rate only for the first subsample; that is, we can reject the hypothesis that

$$
i_{t}=E\left[i_{t+1} \mid \Phi_{t}\right]
$$

where $\Phi_{t}$ represents the information set at time $t$. The idea behind this hypothesis is that risk-neutral banks together with an averaging provision for the reserve requirement will make financial institutions arbitrage away any misalignment between the current rate and its expected future value. Accepting this proposition implies that banks should be looking at funds at different days as perfect substitutes within the same maintenance period. Another set of explanations for our findings, then, arises from analyzing the reasons the literature has given to rationalize observed deviations of the daily rate from the martingale behavior.

The two obvious candidates to justify lack of substitutability of funds are risk aversion and impediments to trade. So it is of no surprise that the papers covering this issue assume one of them or both. For example, Hamilton [10] develops a model in which risk aversion together with reserve accounting conventions, transaction costs and credit line limits can reproduce the observed decrease in the level of the Fed funds rate on Fridays in particular, and over the reserve maintenance period in general. In Bartolini et al. [2], a liquidity preference and transaction costs are responsible for explaining why the level of the overnight rate as well as holdings of reserves tend to increase on settlement day. Another possibility has been provided by Campbell [5]. He uses risk aversion, transaction costs and information problems among banks about the level of aggregate reserve demand to generate more volatility of the funds rate towards the end of the reserve maintenance period. Spindt and Hoffmeister [14] are able to explain this increase in volatility with a model where a market maker dealer adjusts bid and ask rates to maximize profits subject to satisfying a reserve requirement. In such a model, reserve accounting conventions also play a central role.

Although these are valid reasons to rationalize deviations from the martingale behavior, they will hardly account for the fact that these deviations were only significant before January 1999. In general, they would mean that the EMU has had a significant effect on bank's attitudes toward risk, transaction costs or available information, conjectures which are difficult to sustain. Additionally, when we try to use these models, there is some feature of the data that is left unexplained. For example, Hamilton's model is not designed to explain peaks at the end of the reserve maintenance period. Campbell's analysis is local around the full information solution and the implications for the level of the rate depend on parameter values. Finally, Spindt and Hoffmeister's results depend 
on the degree of market power by dealers, which, presumably, has decreased after the unification.

Still, the fact that the martingale hypothesis is rejected is an indication that funds on different days within the same reserve maintenance period are not perfect substitutes. In this paper, instead of generating this lack of substitutability by assuming risk averse agents or impediments to trade, we do so by modeling the role of the operating procedures of central banks in the determination of the overnight rate. In particular, we will show that these instruments of monetary policy make the cost structure of agents demanding reserves in money markets to be non-linear. This non-linearity makes risk neutral agents behave as if they were risk averse and reduces the substitutability of funds across days.

We then use this results to explain the properties of the overnight rate in Germany by analyzing the changes in the operating procedures of the ECB as compared with the ones of the Bundesbank. ${ }^{12}$ These changes are:

- With respect to reserve requirements, both the Bundesbank and the ECB have imposed a reserve maintenance period of one month. This period covered a calendar month in Germany whereas after 1999 it usually starts on the 24th of one month and ends on the 23rd of the following month. Reserves were not remunerated in Germany. On the contrary, the ECB remunerates required reserves at the average rate of its main refinancing operations.

- The conduct of open market operations has been almost identical. In both cases they are the main source of liquidity for the system. Although divided in several categories, main refinancing operations have been the most important of them in both periods. These operations were conducted weekly, under a fixed-rate system, and had similar maturities. ${ }^{13}$

- Finally, the ECB has both a marginal as well as a deposit facility. Under normal circumstances, access to these facility is unrestricted by commercial banks. Before January 1999, the Bundesbank maintained a marginal lending facility (called Lombard loans) that could also be used by banks without limit. It lacked, however a deposit facility.

Could any of these differences explain the observed changes in the behavior of the daily rate in Germany? First, the remuneration of required reserves does not seem to have had any effect. The Eurosystem follows a lagged system for requirements. This means that commercial banks know their requirements at the beginning of the maintenance period. The remuneration is computed over the whole amount and paid after settlement day independently of the profile of accumulation of reserves. It, therefore, should act as a constant in the management problem of banks and should not affect their decisions on when to hold

\footnotetext{
${ }^{12}$ For more details about the operating procedures of the Bundesbank and the ESCB see Deustche Bundesbank [6] and European Central Bank [8].

${ }^{13}$ Since June 2000 , the ECB has been using variable rate tenders in its main refinancing operations.
} 
reserves. Secondly, the "window dressing activities" do not seem to be significantly important in the data, therefore, the change of the settlement day from the end of the month to the 23rd should not have any impact on the behavior of rates. Finally, the only possibility left is to see whether the introduction of the deposit facility by the ECB can rationalize our empirical findings. This is the topic of the next section.

\section{A Theoretical Model of the Overnight Rate}

\subsection{Overview of the Model}

We construct a model that is able to replicate the instruments of both the Bundesbank before January 1999 as well as the ECB after that date. The objective of this section is to explain the basic features of the model, how both sets of instruments are nested, the mechanisms at work and the intuition of the main results.

The economy consists of a central bank and of initially identical, risk-neutral commercial banks (called banks for short) that exchange reserves in a competitive fashion. The central bank uses several instruments to control overnight rates. First, it imposes reserve maintenance periods of $T$ days. During these periods, reserve balances of commercial banks cannot be negative by the end of each day and the accumulated balance over the maintenance period cannot be smaller than a number $R>0$. Second, the central bank provides liquidity for the reserve maintenance period with an open market operation that takes place at the beginning of the first day of the period. At the OMO, reserves are supplied inelastically at a rate denoted $i^{\circ}$. Third, the central bank provides two permanent facilities whose access by commercial banks is unrestricted. There is a marginal lending facility where banks can borrow funds at the interest rate $i^{l}$ and a deposit facility where banks can deposit funds at the rate $i^{d}$.

The timing of events is as follows. All commercial banks start each maintenance period being identical. At the beginning of the first day, the central bank offers funds at an open market operation (OMO henceforth). After the $\mathrm{OMO}$, and during the first day, a market opens where banks can borrow and lend reserves among themselves. At the end of the first day, after the market closes, banks suffer idiosyncratic liquidity shocks that add or drain reserves to their accounts. Then, the central bank register the balances of the banks for purposes of the reserve requirement. On each of the following days until the end of the reserve maintenance period, banks meet in the market, receive the shocks after the market is closed, and the central bank accounts for the reserve levels. There are no more OMOs. Shocks are idiosyncratic in the sense that they do not change the amount of funds in the system, they just reshuffle reserves among banks. We assume that banks do not incur in transaction costs and that there are no credit limits on their borrowing activities. Furthermore, there are no problems of private information in this economy. All variables are publicly known. 
For us, $T$ refers to the last days of the maintenance period. In particular, we construct the model to explain the behavior of the interest rate on the days after the last OMO of the period. This modeling choice is done for several reasons. First, simulations of the model are very computer intensive and it is only possible to do them for a few days. Second, the empirical part has shown that it is the days after the last OMO of the maintenance period the ones where the overnight rate may behave differently. Finally, the last OMO is important for operational purposes since the central bank will not be able to compensate future liquidity shocks with further interventions before the maintenance period is over. In our sample, $T$ can take a value of five at maximum since OMOs had a weekly frequency in Germany. Additionally, the model provides us with a heuristic argument to interpret the behavior of the overnight rate on previous days of the maintenance period.

This model is also design to nest the instrumentation of monetary policy in Germany before and after the EMU. The main differences can be captured by changing the values of the official rates $\left(i^{l}, i^{d}\right.$, and $\left.i^{o}\right)$. Both, the Bundesbank and the ECB have had a marginal lending facility with rates $i^{l}>0$. The ECB has a deposit facility with a rate $i^{d}>0$ which has been 200 basis points below the lending rate. Furthermore, the OMO rate has been always in the middle of the corridor defined by the lending and deposit rates. The Bundesbank did not have a deposit facility which implied $i^{d}=0$ for the first subsample. The OMO rate was always closer to the lending rate than to zero. Below, we will calibrate the model for the two sets of official rates. This exercise will allow us to compare the effects on the overnight rate of changing the implementation of monetary policy.

Besides analyzing the particular differences between the Bundesbank and the ECB, some general implications of the instruments of monetary policy are immediate. The rate of the open market operation determines the average cost of funds over the reserve maintenance period. Therefore, it should be an attractor of the overnight rate. Additionally, the rates of the two facilities bound the market interest rate. No bank will borrow from the market at a rate higher than $i^{l}$ or lend funds at rates lower than $i^{d}$. Apart from these basic features the actual path for the overnight rate in the model is determined from the demand side. We want to show that an active monetary policy is not necessary to reproduce what we observe in the data. In fact, the overall supply of reserves is constant and the only unexpected changes have to do with how it is distributed across banks. The central result in this paper is to show that even in this case, the average interest rate may not be constant over time.

The intuition behind this result is as follows. In the determination of the demand for reserves on any of these $T$ days, banks look at the value of those reserves when they are needed, that is, when the central bank accounts them for the reserve requirement at the end of each day. First, a bank gives a high value to reserves in instances where it has to go to the lending facility. This value is determined by the lending rate. Second, and at the other extreme, funds 
have a low value (the deposit rate) when a bank has excess reserves. ${ }^{14}$ Third, the market rate provides the value of funds in the other, intermediate cases. Of course, when agents decide how much to borrow or lend, they do not know what will happen to their reserves at the end of the day. So, in deciding their demand for funds in the market, banks will balance the marginal costs from borrowing (as represented by the overnight rate) with the expected marginal value of funds as averaged over these three margins. Thus, banks will look at how their behavior affects the probabilities of reaching these three states.

What we exploit in this paper is the fact that demand changes in an asymmetric manner the probabilities of going to the lending facility and of going to the deposit facility. In particular, a decision that increases the probability of having an overdraft today does not influence the probability of recurring to the lending facility in the future. On the contrary, a decision that increases the probability of having excess reserves today increases this probability permanently. In other words, once a bank accumulates all reserves required, they are accumulated for the rest of the maintenance period. This situation is known as banks being "locked-in".

In this setup, how would the demand schedule for reserves behave over the reserve maintenance period? In other words, if interest rates were constant, would be optimal to have a constant demand for reserves? With a constant demand for reserves the probability of using the lending facility is basically constant over time. However, the probability of being locked-in gets larger as time passes. Banks anticipate this effect by decreasing their demand for reserves at the beginning of the period and increasing it towards the end of the period. This behavior puts upward pressure on the daily rate as we get closer to settlement day.

With this model, it is also possible to conclude that changes in the instruments of monetary policy may have an important influence on the behavior of the equilibrium rates. For example, the introduction of a deposit facility should reduce the effects of time on the level of the market rate. By remunerating excess reserves, the facility reduces the costs of having more reserves than what is required by the central bank. This stabilizes the demand for reserves throughout the reserve maintenance period. We will associate different ways of implementing monetary policy with Germany before and after the EMU. Then, we will see that the effects of changing the central bank's instruments imply changes on the overnight rate similar to the ones observed in the data.

\subsection{The Setup}

The model is based on the individual liquidity problem faced by banks when managing their liquidity. Assume an economy inhabited by a central bank and

\footnotetext{
${ }^{14}$ Throughout the paper, the term "excess reserves" is used in a broad sense to indicate all reserves that are not required. They include reserves deposited at the deposit facility of the central bank. It is, therefore, a more general concept than the one used in the banking industry which refers to idle reserves, that is, reserves that are neither required nor deposited in the deposit facility.
} 
a continuum of commercial banks with measure one. The commercial banks (called banks for short) face reserve maintenance periods of $T$ days. On each day $t$ a market opens where banks can exchange reserves through loans with an overnight maturity at an interest rate $i_{t}$. After the market closes, bank $j \in[0,1]$ receives a liquidity shock, $\varepsilon_{t}^{j}$. If $\varepsilon_{t}^{j}$ is positive, the balance of the bank increases and if it is negative the balance decreases. We assume these shocks are i.i.d. across time and banks, with zero mean and drawn from a distribution $F$. Banks care about the management of their liquidity because they have to fulfill two restrictions imposed by the monetary authority. First, current accounts cannot be negative by the end of each day. Second, the accumulated balance over the maintenance period cannot be smaller than a number $R>0$.

Shocks represent uncertainty banks have when trading in the market about the reserves they will have at the time the central bank accounts balances for purposes of reserve regulations. This uncertainty is due to unexpected movements in the accounts due to normal business of banks during the day, the possibility of clerical errors and the fact that banks do not work with real time data when exchanging reserves.

After the shocks hit the banks the monetary authority accounts the reserve balance for purposes of the reserve regulations. If at the end of days $t<T$ a shock makes bank $j$ to have a negative reserve balance, that bank will have to borrow from the central bank's lending facility at the rate $i^{l}$. After the last day, $T$, if the bank does not satisfy the requirement of having an accumulated reserve balance of $R$, it will have to borrow the difference at the lending facility. Borrowing reserves from the monetary authority has a cost because in equilibrium the official lending rate, $i^{l}$, is above the market rate. When a bank has satisfied the reserve requirement and has excess reserves, it can deposit them at the deposit facility and obtain the rate $i^{d}$. The use of the deposit facility is also costly because the deposit rate, $i^{d}$, is below the market rate. Given that the liquidity shock is realized after the market closes, banks do not have perfect control of their use of the facilities. The maturity of these deposits and loans from the central bank is overnight.

In deciding the amounts to borrow or lend in the market at any day, banks take into account their reserve position. This position is summarized by the current account at the beginning of each day, $a_{t}^{j}$, and the amount of reserves a bank $j$ has to accumulate from day $t$ until day $T$ to satisfy its reserve requirement, also know as its deficiency, $r_{t}^{j} \cdot{ }^{15}$ Assume that all banks start day 1 being identical. The initial deficiency is exogenous and determined by the reserve requirement, that is, $r_{1}^{j}=R_{1}=R$, all $j \in[0,1]$. The initial level of reserves, $a_{1}^{j}$, is determined by an open market operation and will be specified below. The pair $s_{t}^{j}=\left(a_{t}^{j}, r_{t}^{j}\right)$ defines the individual state of a bank on any particular day.

Let $m_{t}^{j}$ and $b_{t}^{j}$ be the amount of funds kept by a bank and the ones loaned out in the market at day $t$, respectively. Given the initial level of reserves on

\footnotetext{
${ }^{15}$ In general, lower case letters refer to individual banks while upper case letters refer to per capita market aggregates.
} 
day $t, a_{t}^{j}$, these magnitudes have to satisfy

$$
m_{t}^{j}+b_{t}^{j}=a_{t}^{j}
$$

and

$$
m_{t}^{j} \geq 0
$$

Since the martingale result is based on noncompounding, it is assumed that interests are paid separately so they are not capitalized. This assumption also simplifies the model and means that beginning-of-day reserves evolve exogenously according to

$$
a_{t+1}^{j}=a_{t}^{j}+\varepsilon_{t}^{j}
$$

On the other hand, reserve deficiencies, $r_{t}^{j}$, evolve as

$$
r_{t+1}^{j}=\max \left\{0, r_{t}^{j}-\max \left[0, m_{t}^{j}+\varepsilon_{t}^{j}\right]\right\} .
$$

That is, the reserve balance of the bank at the end of the day $\left(m_{t}^{j}+\varepsilon_{t}^{j}\right)$ is accumulated only if it is positive and deficiencies cannot be negative. Thus, what matters is fulfilling the requirement of accumulating $R$ reserves over the $T$ days and not how much reserves are accumulated on each particular day. Notice, deficiencies are nonincreasing over time. Furthermore, once the deficiency is zero, additional reserves are accumulated in excess. This is what is meant when we state that a bank is "locked-in". In other words, zero is an absorbing state for deficiencies.

The problem for a single bank $j \in[0,1]$ is as follows. It starts day 1 with no reserves. Thus, the first thing to do at the beginning of day 1 is to decide how much reserves, $a_{1}^{j}$, to get from the OMO of the central bank. Once this decision is taken, on every day, it has to compute how much reserves to keep and how much to loan out or borrow in the market. The bank makes these decisions in order to maximize the expected sum of profits over all $T$ days, so the problem is, given the distribution of shocks, $F$, the sequence of market rates $\left\{i_{1}, i_{2}, \ldots\right.$, $\left.i_{T}\right\}$, the initial deficiency, $r_{1}^{j}$, and the initial level of reserves, $a_{1}^{j}$, to decide on the sequence of reserve supplies, $\left\{b_{1}^{j}, b_{2}^{j}, \ldots, b_{T}^{j}\right\}$, to maximize

$$
E_{1}\left[\sum_{t=1}^{T} \pi_{t}^{j}\right],
$$

where $\pi_{t}^{j}$ represents profits of bank $j$ on day $t$. The profits of this bank at day $t$ are

$$
\pi_{t}^{j}=i_{t} b_{t}^{j}-c_{t}^{j}
$$

where $c_{t}^{j}$ represents the end-of-day costs derived from going to the deposit and lending facilities of the central bank. This variable will be specified below. 
The way to solve this problem is by backward induction. With this method, we first solve the problem for all possible individual states and dates starting at day $T$ and working backwards towards the beginning of the maintenance period. This information allows us to find the demand or supply of funds for every bank on every day and to find the sequence of equilibrium rates. Once we know the market clearing rates we are able to compute the profits from having reserves through the maintenance period. Notice these sequences of profits and equilibrium rates are conditioned on the initial level of reserves for each bank, $a_{1}^{j}, j \in[0,1]$, that were obtained at the open market operation at the beginning of day 1 . Then it is possible to see how many reserves banks are willing to obtain from the central bank by comparing the OMO rate with the average value of those funds throughout the maintenance period.

We will calibrate the model for the two sets of official rates that characterize the Bundesbank before and after January 1999 and compare the implied series for the overnight rate.

\subsection{Solution of the Model}

\subsubsection{Problem at $T$}

The problem of an individual bank at settlement day is to maximize with respect to $b_{T}^{j}$

$$
E_{T}\left(\pi_{T}^{j}\right)=i_{t} b_{t}^{j}-E_{T}\left(c_{T}^{j}\right)
$$

given its initial accumulated level of reserves, $a_{T}^{j}$, its reserve deficiency, $r_{T}^{j}$, and the market's interest rate, $i_{T}$. The important point is to compute the variable $c_{T}^{j}$. These costs are equal to

$$
\begin{aligned}
c_{T}^{j}= & i^{l}\left(r_{T}^{j}-m_{T}^{j}-\varepsilon_{T}^{j}\right) I\left[m_{T}^{j}+\varepsilon_{T}^{j}<r_{T}^{j}\right] \\
& -i^{d}\left(m_{T}^{j}+\varepsilon_{T}^{j}-r_{T}^{j}\right) I\left[m_{T}^{j}+\varepsilon_{T}^{j}>r_{T}^{j}\right] .
\end{aligned}
$$

where $I[a]$ is an indicator function that takes value 1 when the statement in brackets is true. The first term on the right hand side represents the costs of borrowing from the monetary authority at the rate $i^{l}$. This happens when balances at the end of the day $\left(m_{T}^{j}+\varepsilon_{T}^{j}\right)$ are not enough to satisfy the requirement $\left(m_{T}^{j}+\varepsilon_{T}^{j}<r_{T}^{j}\right)$. The second term is the revenues from using the deposit facility at the rate $i^{d}$. This happens when the bank has excess reserves at the end of the day $\left(m_{T}^{j}+\varepsilon_{T}^{j}>r_{T}^{j}\right)$. Since in equilibrium the market rate is between $i^{d}$ and $i^{l}$, the bank will use the facilities only if it has to. Notice that the bank will know whether it fulfills the requirement or have excess reserves when the shock is realized after the market is closed so the central bank is the only source of funds or of revenues then. For the same reason, if the bank has reserves in excess of the deficiency, the only source of revenue is the deposit facility. 
Substituting (4) in (8) yields expected profits equal to

$$
\begin{aligned}
E_{T}\left[\pi_{T}^{j}\right]= & i_{T} b_{T}^{j}-i^{l}\left(r_{T}^{j}+b_{T}^{j}-a_{T}^{j}\right) F\left(r_{T}^{j}+b_{T}^{j}-a_{T}^{j}\right) \\
& -i^{d}\left(r_{T}^{j}+b_{T}^{j}-a_{T}^{j}\right)\left[1-F\left(r_{T}^{j}+b_{T}^{j}-a_{T}^{j}\right)\right] \\
& +i^{l} \int_{-\infty}^{r_{T}^{j}+b_{T}^{j}-a_{T}^{j}} \varepsilon f(\varepsilon) d \varepsilon+i^{d} \int_{r_{T}^{j}+b_{T}^{j}-a_{T}^{j}}^{\infty} \varepsilon f(\varepsilon) d \varepsilon .
\end{aligned}
$$

where $f$ is the density function of the shock. The first order condition for a maximum is

$$
i_{T}=i^{l} F\left(r_{T}^{j}+b_{T}^{j}-a_{T}^{j}\right)+i^{d}\left[1-F\left(r_{T}^{j}+b_{T}^{j}-a_{T}^{j}\right)\right] .
$$

This expression says that banks determine the supply of funds in order to equate the marginal revenue of lending an additional unit of reserves with the expected marginal cost of that unit when reserves are needed, that is, when they are computed for the reserve requirement. These costs are $i^{l}$ when the bank's account is overdrawn [with probability $F\left(r_{T}^{j}+b_{T}^{j}-a_{T}^{j}\right)$ ], and $i^{d}$ when the bank is locked-in [with probability $1-F\left(r_{T}^{j}+b_{T}^{j}-a_{T}^{j}\right)$ ]. The supply of reserves in the interbank market by bank $j$ is a function of its state, summarized by the pair $\left(a_{T}^{j}, r_{T}^{j}\right)$, the market rate, $i_{T}$, and the official rates, $i^{l}$ and $i^{d}$. Explicitly, it takes the form

$$
b_{T}^{j}=a_{T}^{j}-r_{T}^{j}+F^{-1}\left(\frac{i_{T}-i^{d}}{i^{l}-i^{d}}\right) .
$$

From this expression we observe that the supply of reserves of bank $j$ is increasing with its initial level of reserves $\left(a_{T}^{j}\right)$, the rate at which the bank exchanges reserves in the market $\left(i_{T}\right)$, and it is decreasing with the reserve deficiency $\left(r_{T}^{j}\right)$, the lending rate $\left(i^{l}\right)$ and the deposit rate $\left(i^{d}\right) .{ }^{16}$

The market clearing interest rate implies that

$$
B_{T}=\int_{0}^{1} b_{T}^{j} d j=0 .
$$

Integrating (11) and operating, the equilibrium rate is equal to

$$
i_{T}=i^{l} F\left(R_{T}-A_{T}\right)+i^{d}\left[1-F\left(R_{T}-A_{T}\right)\right],
$$

where

$$
R_{T}=\int_{0}^{1} r_{T}^{j} d j ; A_{T}=\int_{0}^{1} a_{T}^{j} d j
$$

\footnotetext{
${ }^{16}$ These results and the ones below are conditioned on an interior solution. In some cases boundary conditions may be binding and different expressions may apply. The full solution of the model is included in the appendix.
} 
are the per capita aggregate deficiency and level of reserves for day $T$.

Define the value function $V_{T}$ as the maximized profits at day $T$, that is,

$$
V_{T}\left(s_{T}^{j} ; S_{T}\right)=\max _{b_{T}^{j}} E_{T}\left[\pi_{T}^{j}\right],
$$

where $s_{t}^{j}=\left(a_{t}^{j}, r_{t}^{j}\right)$ represents the individual state of the bank, and $S_{t}$ denotes the aggregate state variable at time $t$ represented by market rates from time $t$ up to time $T$, that is, $S_{t}=\left\{i_{t}, i_{t+1}, \ldots, i_{T}\right\}$. For the last day, $S_{T}=i_{T}$. From

(9) it is easy to see that the marginal value of an additional unit of reserves is

$$
\frac{\partial V_{T}\left(s_{T}^{j} ; S_{T}\right)}{\partial a_{T}^{j}}=i_{T} .
$$

This expression is intuitive. One more unit of reserves can be loaned out in the market and its value should be the market rate. The marginal value of an additional unit of deficiency is

$$
\frac{\partial V_{T}\left(s_{T}^{j} ; S_{T}\right)}{\partial r_{T}^{j}}=-i_{T}
$$

The intuition of this result is as above. Starting the last day with an extra unit of deficiency means not being able to loan it in the market. The marginal cost of this change is the market rate. Expressions (14) and (15) will be used below.

\subsubsection{Problem at $t \leq T-1$}

On days $t \leq T-1$ banks make decisions to maximize the sum of profits until the last day of the maintenance period given the current state and the sequence of rates. Its decisions at time $t$ will affect profits on latter days since they will affect the reserve deficiency in the future. The problem of the bank on day $t \leq T-1$ can then be summarized by the value function $V_{t}\left(s_{t}^{j} ; S_{t}\right)$ defined as

$$
V_{t}\left(s_{t}^{j} ; s_{t}\right)=\max _{b_{t}^{j}} E_{t}\left[\pi_{t}^{j}+V_{t+1}\left(s_{t+1}^{j} ; S_{t+1}\right)\right] .
$$

In this expression, profits are equal to

$$
\begin{aligned}
\pi_{t}^{j}= & i_{t} b_{t}^{j}+i^{l}\left(m_{t}^{j}+\varepsilon_{t}^{j}\right) I\left[m_{t}^{j}+\varepsilon_{t}^{j}<0\right] \\
& -i^{d}\left(r_{t}^{j}-m_{t}^{j}-\varepsilon_{t}^{j}\right) I\left[m_{t}^{j}+\varepsilon_{t}^{j}>r_{t}^{j}\right] .
\end{aligned}
$$

Apart from the revenues (costs) of lending (borrowing) in the market, banks incur in revenues and costs when borrowing from the central bank when the end-of-day balances are negative or deposit in the deposit facility if they have 
excess reserves. As before, using (4) and taking expectations produces

$$
\begin{aligned}
E_{t}\left[\pi_{t}^{j}\right] & =i_{t} b_{t}^{j}-i^{l}\left(b_{t}^{j}-a_{t}^{j}\right) F\left(b_{t}^{j}-a_{t}^{j}\right) \\
& -i^{d}\left(r_{t}^{j}+b_{t}^{j}-a_{t}^{j}\right)\left[1-\left(F r_{t}^{j}+b_{t}^{j}-a_{t}^{j}\right)\right] \\
& +i^{l} \int_{-\infty}^{b_{t}^{j}-a_{t}^{j}} \varepsilon f(\varepsilon) d \varepsilon+i^{d} \int_{r_{t}^{j}+b_{t}^{j}-a_{t}^{j}}^{\infty} \varepsilon f(\varepsilon) d \varepsilon .
\end{aligned}
$$

To compute the second term in (16) notice that from (6),

$$
r_{t 1}^{j}=\max \left\{0, r_{t}^{j}-\max \left[0, m_{t}^{j}+\varepsilon_{t}^{j}\right]\right\}
$$

so,

$$
\begin{gathered}
r_{t+1}^{j}=r_{t}^{j} ; \quad \text { if } \varepsilon_{t}^{j} \leq-m_{t}^{j}, \\
r_{t+1}^{j}=d_{t}^{j}-m_{t}^{j}-\varepsilon_{t}^{j} ; \quad \text { if }-m_{t}^{j} \leq \varepsilon_{t}^{j} \leq r_{t}^{j}-m_{t}^{j},
\end{gathered}
$$

and

$$
r_{t+1}^{j}=0 ; \quad \text { if } r_{t}^{j}-m_{t}^{j} \leq \varepsilon_{t}^{j} .
$$

Then

$$
\begin{aligned}
E_{t}\left[V_{t+1}\left(s_{t+1}^{j} ; S_{t+1}\right)\right] & =\int_{-\infty}^{-m_{t}^{j}} V_{t+1}\left(r_{t}^{j}, a_{t+1}^{j} ; S_{t+1}\right) f(\varepsilon) d \varepsilon \\
& +\int_{-m_{t}^{j}}^{r_{t}^{j}-m_{t}^{j}} V_{t+1}\left(r_{t}^{j}-m_{t}^{j}-\varepsilon, a_{t+1}^{j} ; S_{t+1}\right) f(\varepsilon) d \varepsilon \\
& +\int_{r_{t}^{j}-m_{t}^{j}}^{\infty} V_{t+1}\left(0, a_{t+1}^{j} ; S_{t+1}\right) f(\varepsilon) d \varepsilon .
\end{aligned}
$$

Again, using (4), the first order condition with respect to $b_{t}^{j}$ gives

$$
\begin{aligned}
i_{t}= & i^{l} F\left(b_{t}^{j}-a_{t}^{j}\right)+i^{d}\left[1-F\left(r_{t}^{j}+b_{t}^{j}-a_{t}^{j}\right)\right] \\
& -\int_{b_{t}^{j}-a_{t}^{j}}^{r_{t}^{j}+b_{t}^{j}-a_{t}^{j}} \frac{\partial V_{t+1}\left(r_{t+1}^{j}, a_{t+1}^{j} ; S_{t+1}\right)}{\partial r_{t+1}^{j}} f(\varepsilon) d \varepsilon
\end{aligned}
$$

which generates the supply of funds on any day $t \leq T-1$. The intuition is the same as before. When deciding the supply of funds, banks equate the marginal 
revenue of lending funds (as represented by the market rate) to the expected marginal cost. The expected marginal cost is an average of the marginal costs after the shock hits the bank. If the bank is not locked-in $\left(r_{t}^{j}>0\right)$, there are three possibilities, depending on the size of the shock:

- For shocks satisfying $\epsilon_{t}^{j}<-m_{t}^{j}$, the bank will have an overdraft at the end of the day and will have to borrow from the central bank. In that case, the marginal cost of funds would be $i^{l}$. This happens with probability $F\left(b_{t}^{j}-a_{t}^{j}\right)$.

- On the opposite side, for shocks satisfying $\epsilon_{t}^{j}>r_{t}^{j}-m_{t}^{j}$, the bank accumulates so much reserves that it will be locked-in. In such cases, the marginal cost of funds will be $i^{d}$. This happens with probability $1-F\left(r_{t}^{j}+b_{t}^{j}-a_{t}^{j}\right)$.

- Finally, for intermediate cases, $-m_{T-1}^{j}<\epsilon_{T-1}<r_{T-1}^{j}-m_{T-1}^{j}$, the bank accumulates reserves but still have a reserve deficiency that needs to be resolved in the future. In this case, the marginal cost of funds should be equal to the marginal value of funds in the following day.

With expression (19) it is not possible to compute the equilibrium interest rate for $t \leq T-1$ explicitly. The following section will approximate this rate in a numerical example.

The partial derivative of the value function with respect to $a_{T-1}^{j}$ is

$$
\frac{\partial V_{t}}{\partial a_{t}^{j}}=i_{t}+\int_{-\infty}^{\infty} \frac{\partial V_{t+1}}{\partial a_{t+1}^{j}} f(\varepsilon) d \varepsilon=\sum_{\tau=t}^{T} i_{\tau} .
$$

What is the value that a bank associates with having an additional unit of reserves at day $t$ ? This bank can lend that unit on day $t$ and on future days. This decision will not affect its state on any day and will increase its profits by $\sum_{\tau=t}^{T} i_{\tau}$. In other words, having an additional unit of reserves on day $t$, means, on average, a permanent addition for the balance of the bank and, therefore, its value is the accumulated expected revenue of that unit for the rest of the reserve maintenance period. For a single bank, this value is represented by the sum of the market rates up to day $T$.

The partial derivative of the value function with respect to $r_{t}^{j}$ is

$$
\frac{\partial V_{t}}{\partial r_{t}^{j}}=-i^{d}\left[1-F\left(r_{t}^{j}-m_{t}^{j}\right)\right]+\int_{-\infty}^{r_{t}^{j}-m_{t}^{j}} \frac{\partial V_{t+1}}{\partial r_{t+1}^{j}} f(\varepsilon) d \varepsilon .
$$

What is the value that a bank associates with having a unit of deficiency less on day $t$ ? This value depends on what its situation is at the end of $t$. If the bank ends up the day locked-in, starting the day with a smaller deficiency has a low value, the deposit rate. This is the first term of the right hand side of (21). In all other cases, a smaller deficiency decreases $r_{t}^{j}$ permanently and the value of 
this event is determined by $\partial V_{t+1}^{j} / \partial r_{t+1}^{j}$. This is the second term. Notice the mechanism here is different than the mechanism of increasing initial reserves, $a_{t}^{j}$. The value we assign to have a smaller deficiency depends on the probability that this reduction is kept over time which is determined by the probability of not being locked-in. On the contrary, having an additional unit of reserves implies a permanent addition independently of the shocks that may happen in the future.

\subsubsection{The open market operation at $t=1$}

The initial level of reserves is injected through an open market operation that takes place at the beginning of day 1 , before the market opens. It is assumed that the central bank supplies reserves inelastically at the interest rate $i^{o}$ through loans with a maturity of $T$ days. All banks participating in the open market operation are identical. They have no funds and have to accumulate $R$ reserves through the next $T$ days. The problem for bank $j$ is to choose the reserves borrowed from the central bank, $a_{1}^{j}$, to maximize expected profits for the maturity of the loan, $T$ days. These expected profits are, therefore,

$$
\pi_{\text {omo }}^{j}=V_{1}\left(R, a_{1}^{j} ; S_{1}\right)-T i^{o} a_{1}^{j} .
$$

The first order condition that determines the initial level of reserves for these banks is

$$
i^{o}=\frac{1}{T} \frac{\partial V_{1}}{\partial a_{1}^{j}}=\frac{1}{T} \sum_{\tau=1}^{T} i_{\tau} .
$$

Since all banks start from the same situation, they will demand the same amount from the OMO so we can write $a_{1}^{j}=A_{1}$. Notice, the bank considers itself a small player in the economy so that its bid in the open market operation does not affect equilibrium rates. The intuition from expression (22) should be clear. Banks bid for official reserves up to the point where the daily marginal cost of those reserves (the OMO rate) equals the expected average marginal value of those reserves throughout the maturity of the loan given by the average of the sequence of market rates.

Expression (22) also helps understand why the OMO rate is an attractor of the market rate. When the OMO rate is large relative to the lending and deposit rate, banks understand that reserves are expensive and bid a smaller amount. With fewer reserves the probability of having an overdraft increases and so does the market rate on average over the period. Notice also, this condition imposes a restriction on the average of the market rates over the maintenance period but does not say anything about the actual path. In fact, we will show that this path is increasing and this feature is linked to the evolution of the probabilities of going to the lending and deposit facility together with the characteristic of being locked-in as an absorbing state. 


\subsection{The Martingale Hypothesis}

Because of the continuum of banks with measure one, the law of large numbers apply in this economy. This means that there is no aggregate risk so the particular form of the martingale hypothesis is whether equilibrium rates are constant over the maintenance period or not. So, is it true that $i_{t}=i_{t+1}$ in this model? From the previous discussion, it is clear that the answer to this question depends on, whether at constant rates banks keep the aggregate demand of funds equal to the constant aggregate supply for the whole maintenance period. Expression (19) expresses the demand (negative supply) for funds on any day $t<T$. We see that the evolution of demand $\left(-b_{t}^{j}\right)$ over time depends upon the evolution of the measures associated with the three sets for which bank $j$

1. has an overdraft,

$$
\Phi_{1 t} \equiv\left\{\epsilon: \epsilon_{t}<b_{t}^{j}-a_{t}^{j}\right\}
$$

2. accumulates reserves,

$$
\Phi_{2 t} \equiv\left\{\epsilon: b_{t}^{j}-a_{t}^{j}<\epsilon_{t}<r_{t}^{j}+b_{t}^{j}-a_{t}^{j}\right\}
$$

or

3. is locked-in,

$$
\Phi_{3 t} \equiv\left\{\epsilon: \epsilon_{t}>r_{t}^{j}+b_{t}^{j}-a_{t}^{j}\right\}
$$

Intuitively, with a constant demand for funds, the bank expects the probability of being overdraft to be roughly constant throughout the reserve maintenance period. On the other hand, the probability of going to the deposit facility should be increasing over time since once we have excess reserves on one day we are locked-in for the rest of the maintenance period. Banks anticipate this and postpone demand. With a constant supply of reserves this should put upward pressure on the interest rate towards settlement day.

It is not possible to give a general assessment about the size and sign of these deviations from the martingale behavior. To get an answer to this question, we present a numerical example where the behavior of the interest rate can be computed.

\subsubsection{A Numerical Example}

In this section, we calibrate the model to replicate the daily market for funds in Germany before and after the beginning of the EMU. The differences between these two markets are captured by two sets of values for the official rates. The rest of parameters are common across the two economies to show that changes in the official rates can be responsible for the stylized facts documented in section 2 . 
The common parameters are $T, R$, and $\sigma$. The length of the maintenance period, $T$, takes value of 4 days. As mentioned before, one way to think about this length is that we are finding the interest rates for the days after the last open market operation of the period. For computational reasons, 4 was the largest we could compute. The reserve requirement is $R=400$ which means that banks have to accumulate an average of 100 units per day. This value is chosen so that we can interpret the numbers below as percentages of daily requirements. The shock is assumed to follow a normal distribution with zero mean and standard deviation $\sigma=100$. This number is calibrated with the aggregate transactions observed in the market which represents approximately 50 percent of the average daily requirement. The distribution of the shock is approximated with a grid at 10 unit intervals large enough to capture three times its standard deviation.

The official rates are calibrated as follows. Since both the Bundesbank and the ECB had a lending facility, we keep the lending rate constant and set it to $i^{l}=5$ percent. Then, we leave $i^{d}$ to take two values in order to differentiate between Germany before and after the EMU. The value $i^{d}=0$ represents Germany before Stage Three of the EMU. Remember Germany did not have a deposit facility then. Germany after January 1999 is represented by $i^{d}=3$. This value for the deposit rate produces a band with a width of 200 basis point as we observe in the Euro area.

With respect to the OMO rate, we proceed as follows. Instead of imposing a rate, we solve the model for different values of $A_{1}$ in the set $A_{1} \in[70,130]$ and compute the average marginal value of funds, that is, the right-hand side of expression (22). This gives us the demand schedule of the market for funds in the open market operation. Table 5 presents, for each value of $A_{1}$, the sequence of equilibrium rates (columns $i_{1}$ to $i_{4}$ ) as well as the average marginal value of funds as of day one (column $A M V F$ ) for the case of Germany before the EMU, that is, without a deposit facility $\left(i^{d}=0\right)$.

Table 5

Equilibrium rates for $i^{d}=0$

\begin{tabular}{cccccc}
\hline$A_{1}$ & $A M V F$ & $i_{1}$ & $i_{2}$ & $i_{3}$ & $i_{4}$ \\
\hline 70 & 3.96 & 3.87 & 3.92 & 3.98 & 4.07 \\
80 & 3.45 & 3.37 & 3.41 & 3.47 & 3.54 \\
90 & 2.83 & 2.76 & 2.80 & 2.84 & 2.90 \\
100 & 2.18 & 2.11 & 2.15 & 2.19 & 2.26 \\
110 & 1.67 & 1.60 & 1.64 & 1.68 & 1.76 \\
120 & 1.25 & 1.19 & 1.22 & 1.26 & 1.35 \\
130 & 0.93 & 0.87 & 0.90 & 0.93 & 1.02 \\
\hline
\end{tabular}

In order to know how much banks will be willing to bid at a particular OMO rate, we just have to look at the value of $A_{1}$ with an average marginal value of funds equal to the rate of the open market operation. The OMO rate in Germany before 1999 was between 3 and 3.5 percent. This means that banks should bid around 80 units of reserves in the open market operation which will 
have the system short of the daily requirement by 20 units. Banks do this because, given that reserves are expensive relative to the deposit and lending rates, they decide to play the game of obtaining them in the future through the shocks. We observe that interest rates increase in these four days by 17 basis points. To us this is a sizable amount given that we have an economy without aggregate risk, where banks are heterogeneous on three days only and with perfect markets. In fact, a peak of similar magnitude in the path for the overnight rate is a feature shared by all lines in the table.

After the EMU, the Eurosystem created a band for the overnight rate of 200 basis points with the OMO rate set at the middle point. We reproduce this fact in the example by setting the deposit rate at 3 percent. Table 6 collects the results for this case. Still we find the peaks as before but their magnitude is much smaller. For example, for the equilibrium sequence closest to the OMO rate of 4 percent, the overnight rate increases by 5 basis points. This means that before the EMU the increments in the overnight rate were more than three times larger than the corresponding increments after 1999.

Table 6

Equilibrium rates for $i^{d}=3$

\begin{tabular}{cccccc}
\hline$A_{1}$ & $A M V F$ & $i_{1}$ & $i_{2}$ & $i_{3}$ & $i_{4}$ \\
\hline 70 & 4.59 & 4.56 & 4.57 & 4.60 & 4.64 \\
80 & 4.38 & 4.35 & 4.37 & 4.39 & 4.42 \\
90 & 4.13 & 4.11 & 4.12 & 4.14 & 4.16 \\
100 & 3.86 & 3.84 & 3.85 & 3.87 & 3.90 \\
110 & 3.67 & 3.65 & 3.66 & 3.68 & 3.71 \\
120 & 3.49 & 3.47 & 3.48 & 3.49 & 3.53 \\
130 & 3.37 & 3.35 & 3.36 & 3.37 & 3.41 \\
\hline
\end{tabular}

\subsubsection{Intuition and Policy Implications}

To understand the intuition behind Tables 5 and 6 we should remind the reader that the expressions determining the funds rate have been derived from maximization conditions. Therefore, there is an implicit arbitrage argument in those expressions. At the equilibrium prices, banks should not have any incentive to move reserves between different days of the reserve maintenance period in order to increase the objective function.

When banks decide their demand for reserves within the maintenance period they have to weight the different costs and benefits of increasing their deposits at the central bank. The cost of not having enough reserves is the lending rate which is above the daily rate. The cost of having too many reserves is the possibility of being locked-in earlier in the period and to receive the deposit rate which is smaller than the overnight rate. Clearly, whether the bank will be indifferent to substitute reserves will depend not only on the average rate but also on the likelihood of these two outcomes in the future which are measured by the probabilities of having a shock belonging to the sets $\Phi_{1 t}$ and $\Phi_{3 t}$ in (23) 
and (25), respectively. Define these probabilities as

$$
p_{k t}=\operatorname{prob}\left\{\epsilon_{t} \in \Phi_{k t}\right\}, \quad k=1,2,3 .
$$

The number $p_{1 t}$ corresponds to the probability of ending day $t$ with an overdraft while the number $p_{3 t}$ corresponds to ending day $t$ being locked-in. Since the shock is i.i.d. with zero mean, each bank expects its level of reserves, $a_{t}^{j}$, to be constant. For the same reason, the bank expects the reserve deficiency, $r_{t}^{j}$, to be decreasing over time. This implies that, as we get closer to $T, p_{3 t}$ should be increasing while $p_{1 t}$ should be constant except for the last day.

Tables 7 and 8 show the probabilities of ending the day with an overdraft or with excess reserves for values of the deposit rate equal to 0 and 3 , respectively.

Table 7

Probability of ending the day with overdraft and locked-in for $i^{d}=0$

\begin{tabular}{c|cccc|cccc}
\hline$A_{1}$ & $p_{11}$ & $p_{12}$ & $p_{13}$ & $p_{14}$ & $p_{31}$ & $p_{32}$ & $p_{33}$ & $p_{34}$ \\
\hline 70 & 0.2266 & 0.2403 & 0.2584 & 0.7642 & 0.0000 & 0.0161 & 0.0800 & 0.2374 \\
80 & 0.1977 & 0.2117 & 0.2282 & 0.6707 & 0.0000 & 0.0239 & 0.1184 & 0.3293 \\
90 & 0.1710 & 0.1836 & 0.2016 & 0.5639 & 0.0000 & 0.0368 & 0.1709 & 0.4361 \\
100 & 0.1468 & 0.1568 & 0.1743 & 0.4520 & 0.0016 & 0.0555 & 0.2405 & 0.5480 \\
110 & 0.1251 & 0.1333 & 0.1487 & 0.3520 & 0.0022 & 0.0787 & 0.3190 & 0.6480 \\
120 & 0.1056 & 0.1120 & 0.1263 & 0.2700 & 0.0030 & 0.1083 & 0.4021 & 0.7300 \\
130 & 0.0885 & 0.0944 & 0.1043 & 0.2040 & 0.0040 & 0.1432 & 0.4851 & 0.7960 \\
\hline
\end{tabular}

Table 8

Probability of ending the day with overdraft and locked-in for $i^{d}=3$

\begin{tabular}{c|cccc|cccc}
\hline$A_{1}$ & $p_{11}$ & $p_{12}$ & $p_{13}$ & $p_{14}$ & $p_{31}$ & $p_{32}$ & $p_{33}$ & $p_{34}$ \\
\hline 70 & 0.2266 & 0.2374 & 0.2595 & 0.7681 & 0.0000 & 0.0162 & 0.0807 & 0.2319 \\
80 & 0.1977 & 0.2125 & 0.2285 & 0.6723 & 0.0000 & 0.0238 & 0.1177 & 0.3277 \\
90 & 0.1710 & 0.1836 & 0.2029 & 0.5640 & 0.0000 & 0.0368 & 0.1696 & 0.4360 \\
100 & 0.1468 & 0.1541 & 0.1748 & 0.4500 & 0.0016 & 0.0563 & 0.2427 & 0.5500 \\
110 & 0.1251 & 0.1333 & 0.1496 & 0.3550 & 0.0022 & 0.0787 & 0.3175 & 0.6450 \\
120 & 0.1056 & 0.1119 & 0.1229 & 0.2650 & 0.0030 & 0.1088 & 0.4072 & 0.7350 \\
130 & 0.0885 & 0.0947 & 0.1030 & 0.2050 & 0.0040 & 0.1431 & 0.4877 & 0.7950 \\
\hline
\end{tabular}

Several conclusions can be drawn from these tables. First, the probabilities are very similar for $i^{d}=0$ and $i^{d}=3$. This means that banks decide on their borrowing and lending depending on the path of interest rates relative to the band determined by the lending and deposit rate. Second, the larger the initial level of reserves, the larger the probability of being locked-in and the smaller the probability of being overdraft. Finally, as we argued above, for any level of $A_{1}$, the probability of going to the lending facility is fairly constant throughout the reserve maintenance period, while the probability of going to the deposit facility is steadily increasing over time.

There are two elements that may influence the path of the overnight rate: the width of the band between the lending and deposit rate and the relative 
position of the OMO rate within the band. Remember banks care about the costs of going to the lending and deposit facility but being locked-in has an extra cost in the sense that it is an absorbing state. As we said before, this perception would imply a tendency of the banks to postpone their holding of reserves to avoid that risk. Those banks following that strategy, will have to pay a higher interest rate when they want to hold reserves, at the end of the maintenance period. Therefore, with an increasing path for the overnight rate, a bank is indifferent between holding reserves at the beginning (when they pay a lower rate but increase the risk of being locked-in) or at the end of the maintenance period (when they pay a higher rate but avoid the risk of being locked-in).

Given a band for the interest rate we can understand why changing the OMO rate affects the average of the overnight rate for the maintenance period but it does not affect the difference between the rates on the last and first days. By increasing the OMO rate, the central bank increases the marginal cost of funds for the period. Commercial banks react to this situation by decreasing their demand for official reserves and letting the system go short of the requirement. This increases the average market rate because it makes more likely the possibility of going to the lending facility throughout the whole maintenance period. However, although the probability of being locked-in has decreased, the difference between the market rate and the deposit rate has increased. Thus, even though having excess reserves is less likely, it is more expensive in terms of opportunity cost which compensates the reduction in its probability. In the opposite case, when the OMO rate is reduced, the cost decreases but the event of being locked-in is more likely.

On the other hand, the width of the band affects the observed path of the overnight rate. By increasing the deposit rate towards the lending rate, the central bank is reducing the relative cost of being locked-in and the inclination of banks to postpone demand to avoid that risk. This example shows that the spread between the lending and the deposit rate plays a crucial role in the determination of the statistical properties of the overnight rate. This is important because all monetary systems have implicitly or explicitly a band for the overnight rate. For systems without standing facilities this band is defined between the discount rate (plus all non-pecuniary costs associated with borrowing from the central bank) and zero. Interestingly, the pattern of increasing rates has been documented for other economies without standing facilities, specially the US. ${ }^{17}$ So, this model can shed light in the explanation of those observations as well.

We believe these results have important implications for policy. First, they show that central banks could achieve a stable profile for the overnight rate in two ways. On the one hand, they could actively try to reduce the volatility of that rate by intervening in the market at the end of each maintenance period. Alternatively, they could passively obtain that goal by setting a corridor for the daily rate with the two standing facilities. The resources needed to follow the first option seem much larger than what is required to design the second

\footnotetext{
${ }^{17}$ See, among otheres, Bartolini et al. [2] and Hamilton [10].
} 
one. This discussion suggests that the introduction of two standing facilities appears as a preferable system to stabilize the overnight rate. Second, the important measure of how expansionary or contractionary monetary policy is in one country, in terms of the associated demand for reserves for a given OMO rate, does not only depend on the level of the OMO rate but also on that level relative to the band for the overnight rate. So, a central bank that reduces the OMO rate together with the limits of the band does not necessarily mean that is following a more expansionary policy.

Once we know how the overnight rate evolves after the last OMO, we can also argue how it should behave on any other day of the maintenance period. The principle is still the same. The daily rate is determined by demands and supplies that are decided on the basis of the expected marginal cost of funds at the end of each day. At the beginning of the reserve maintenance period, the probability of being locked-in is basically zero. The probability of having an overdraft is not zero but small. So, in determining the marginal cost of funds, the only important term is

$$
i_{t} \simeq-\int_{b_{t}^{j}-a_{t}^{j}}^{r_{t}^{j}+b_{t}^{j}-a_{t}^{j}} \frac{\partial V_{t+1}\left(r_{T}^{j}, a_{t+1}^{j} ; s_{t+1}\right)}{\partial r_{t+1}^{j}} f(\varepsilon) d \varepsilon,
$$

with

$$
\frac{\partial V_{t+1}\left(r_{T}^{j}, a_{t+1}^{j} ; s_{t+1}\right)}{\partial r_{t+1}^{j}} \simeq-i_{t+1} .
$$

If banks do not expect changes in the conduct of monetary policy in the future associated with changes in the OMO rate, the overnight rate should be close to a martingale.

\section{Conclusions}

This paper presents evidence about the time series properties of the overnight rate in Germany. It shows that the process governing this rate has become closer to a martingale after the start of the EMU. Before January 1999, this series exhibited significant peaks associated with end of reserve maintenance periods.

We develop a model of reserve management by banks to explain the changes in the mean process of the daily rate. An important theoretical implication is that, with an averaging provision for the reserve requirement, banks do not see funds on different days of the same reserve maintenance period as perfect substitutes even if they expect rates to be constant in the future. In fact, this type of behavior implies a process for the interest rate that tends to be higher as we approach settlement day. The paper also shows that these deviations from the martingale hypothesis are reduced as the spread between the central 
bank's lending and deposit rates decreases. We obtain these results neither by invoking market frictions, nor by imposing noncompetitive behavior. It is just a consequence of paying particular attention in modeling the opportunity costs faced by risk neutral banks and how these costs change as we move along the reserve maintenance period.

Patterns for the mean process of the overnight rate characterized by increases at the end of the reserve maintenance period have been documented before. The explanations for such patterns were exclusively based on market frictions or risk averse behavior. Our point is that we do not need those ingredients to understand deviations from the martingale hypothesis. The way we see market frictions or risk aversion is as devices that amplify a mechanism that is in place even in economies with risk neutral agents and no impediments to trade.

With respect to our particular application, our explanation seems more plausible than competing ones given that we are dealing with the same economy where attitudes toward risk or market institutions have changed little. Summarizing, it seems that the institutional framework of the new system has been an important element in producing a smoother patter for the market rate in Germany. In particular, we can trace the origin of this change to the introduction of a deposit facility by the ECB that it was not in place before the EMU.

\section{A Solution of the Model}

In the solution of the model we use the following results. Define the following functions:

$$
\begin{gathered}
H_{1}(x)=\int_{-\infty}^{x} \varepsilon f(\varepsilon) d \varepsilon, \\
H_{2}(x)=\int_{x}^{\infty} \varepsilon f(\varepsilon) d \varepsilon, \\
H_{3}(x)=\int_{-\infty}^{x} v(x, \varepsilon) f(\varepsilon) d \varepsilon,
\end{gathered}
$$

and

$$
H_{4}(x)=\int_{x}^{\infty} v(x, \varepsilon) f(\varepsilon) d \varepsilon
$$

Then,

$$
\frac{d H_{1}(x)}{d x}=x f(x),
$$




$$
\begin{gathered}
\frac{d H_{2}(x)}{d x}=-x f(x), \\
\frac{d H_{3}(x)}{d x}=x f(x)+\int_{-\infty}^{x} \frac{\partial v(x, \varepsilon)}{\partial x} f(\varepsilon) d \varepsilon,
\end{gathered}
$$

and

$$
\frac{d H_{4}(x)}{d x}=-x f(x)+\int_{x}^{\infty} \frac{\partial v(x, \varepsilon)}{\partial x} f(\varepsilon) d \varepsilon .
$$

\section{A.1 Problem at $T$}

Define

$$
V_{T}\left(s_{T}^{j} ; s_{T}\right)=\max _{b_{T}^{j}} E_{T}\left[\pi_{T}^{j}\right]
$$

subject to

$$
b_{T}^{j} \leq \min \left(a_{T}^{j}, 0\right)
$$

with

$$
\begin{aligned}
E_{T}\left[\pi_{T}^{j}\right]= & i_{T} b_{T}^{j}-i^{l}\left(r_{T}^{j}+b_{T}^{j}-a_{T}^{j}\right) F\left(r_{T}^{j}+b_{T}^{j}-a_{T}^{j}\right) \\
& -i^{d}\left(r_{T}^{j}+b_{T}^{j}-a_{T}^{j}\right)\left[1-F\left(r_{T}^{j}+b_{T}^{j}-a_{T}^{j}\right)\right] \\
& +i^{l} \int_{-\infty}^{r_{T}^{j}+b_{T}^{j}-a_{T}^{j}} \varepsilon f(\varepsilon) d \varepsilon+i^{d} \int_{r_{T}^{j}+b_{T}^{j}-a_{T}^{j}}^{\infty} \varepsilon f(\varepsilon) d \varepsilon .
\end{aligned}
$$

The first order condition for a maximum is

$$
\begin{aligned}
0= & i_{T}-i^{l} F\left(r_{T}^{j}+b_{T}^{j}-a_{T}^{j}\right)-i^{l}\left(r_{T}^{j}+b_{T}^{j}-a_{T}^{j}\right) f\left(r_{T}^{j}+b_{T}^{j}-a_{T}^{j}\right) \\
& -i^{d}\left[1-F\left(r_{T}^{j}+b_{T}^{j}-a_{T}^{j}\right)\right]+i^{d}\left(r_{T}^{j}+b_{T}^{j}-a_{T}^{j}\right) f\left(r_{T}^{j}+b_{T}^{j}-a_{T}^{j}\right) \\
& +i^{l}\left(r_{T}^{j}+b_{T}^{j}-a_{T}^{j}\right) f\left(r_{T}^{j}+b_{T}^{j}-a_{T}^{j}\right)-i^{d}\left(r_{T}^{j}+b_{T}^{j}-a_{T}^{j}\right) f\left(r_{T}^{j}+b_{T}^{j}-a_{T}^{j}\right) .
\end{aligned}
$$

Rearranging this expression yields (10)

$$
i_{T}=i^{l} F\left(r_{T}^{j}+\widehat{b}_{T}^{j}-a_{T}^{j}\right)+i^{d}\left[1-F\left(r_{T}^{j}+\widehat{b}_{T}^{j}-a_{T}^{j}\right)\right] .
$$

Call $\widehat{b}_{T}^{j}$ the interior solution, which satisfies

$$
\widehat{b}_{T}^{j}=a_{T}^{j}-r_{T}^{j}+F^{-1}\left(\frac{i_{T}-i^{d}}{i^{l}-i^{d}}\right) .
$$


The maximand in (28) is determined by

$$
b_{T}^{j}=\min \left[\max \left(a_{T}^{j}, 0\right), \widehat{b}_{T}^{j}\right] .
$$

If $a_{T}^{j} \geq 0$, the constraint $b_{T}^{j} \leq a_{T}^{j}$ is binding if

$$
i_{T}>i^{l} F\left(r_{T}^{j}\right)+i^{d}\left[1-F\left(r_{T}^{j}\right)\right] .
$$

In this case,

$$
\begin{gathered}
b_{T}^{j}=a_{T}^{j}, \\
\frac{\partial V_{T}\left(s_{T}^{j} ; s_{T}\right)}{\partial r_{T}^{j}}=-i^{l} F\left(r_{T}^{j}\right)-i^{d}\left[1-F\left(r_{T}^{j}\right)\right]>-i_{T},
\end{gathered}
$$

and

$$
\frac{\partial V_{T}\left(s_{T}^{j} ; s_{T}\right)}{\partial a_{T}^{j}}=i_{T}
$$

If $a_{T}^{j}<0$, the constraint $b_{T}^{j} \leq 0$ is binding if

$$
i_{T}<i^{l} F\left(r_{T}^{j}-a_{T}^{j}\right)+i^{d}\left[1-F\left(r_{T}^{j}-a_{T}^{j}\right)\right] .
$$

In this case,

$$
b_{T}^{j}=0,
$$

and

$\frac{\partial V_{T}\left(s_{T}^{j} ; s_{T}\right)}{\partial r_{T}^{j}}=-i^{l} F\left(r_{T}^{j}-a_{T}^{j}\right)-i^{d}\left[1-F\left(r_{T}^{j}-a_{T}^{j}\right)\right]=-\frac{\partial V_{T}\left(s_{T}^{j} ; s_{T}\right)}{\partial a_{T}^{j}}<-i_{T}$.

\section{A.2 Problem at $t<T$}

Define

$$
V_{t}\left(s_{t}^{j} ; s_{t}\right)=\max _{b_{t}^{j}} E_{t}\left[\pi_{t}^{j}+V_{t}\left(s_{t+1}^{j} ; s_{t+1}\right)\right] .
$$

subject to

$$
b_{t}^{j} \leq \min \left(a_{t}^{j}, 0\right)
$$


with

$$
\begin{aligned}
E_{t}\left[\pi_{t}^{j}\right] & =i_{t} b_{t}^{j}-i^{l}\left(b_{t}^{j}-a_{t}^{j}\right) F\left(b_{t}^{j}-a_{t}^{j}\right) \\
& -i^{d}\left(r_{t}^{j}+b_{t}^{j}-a_{t}^{j}\right)\left[1-F\left(r_{t}^{j}+b_{t}^{j}-a_{t}^{j}\right)\right] \\
& +i^{l} \int_{-\infty}^{b_{t}^{j}-a_{t}^{j}} \varepsilon f(\varepsilon) d \varepsilon+i^{d} \int_{r_{t}^{j}+b_{t}^{j}-a_{t}^{j}}^{\infty} \varepsilon f(\varepsilon) d \varepsilon,
\end{aligned}
$$

and

$$
\begin{aligned}
E_{t}\left[V_{t+1}\left(s_{t+1}^{j} ; s_{t+1}\right)\right] & =\int_{-\infty}^{b_{t}^{j}-a_{t}^{j}} V_{t+1}\left(r_{t}^{j}, a_{t+1}^{j} ; s_{t+1}\right) f(\varepsilon) d \varepsilon \\
& +\int_{b_{t+1}^{j}+b_{t+1}^{j}-a_{t+1}^{j}}^{b_{t+1}^{j}-a_{t+1}^{j}} V_{t+1}\left(r_{t}^{j}+b_{t}^{j}-a_{t}^{j}-\varepsilon, a_{t+1}^{j} ; s_{t+1}\right) f(\varepsilon) d \varepsilon \\
& +\int_{r_{t+1}^{j}+b_{t+1}^{j}-a_{t+1}^{j}}^{\infty} V_{T}\left(0, a_{t+1}^{j} ; s_{t+1}\right) f(\varepsilon) d \varepsilon .
\end{aligned}
$$

The interior solution $\left(\widehat{b}_{t}^{j}\right)$ satisfies

$$
\begin{aligned}
i_{t}= & i^{l} F\left(\widehat{b}_{t}^{j}-a_{t}^{j}\right)+i^{d}\left[1-F\left(r_{t}^{j}+\widehat{b}_{t}^{j}-a_{t}^{j}\right)\right] \\
& -\int_{\hat{b}_{t}^{j}-a_{T-1}^{j}}^{r_{T-1}^{j}+\widehat{b}_{t}^{j}-a_{T-1}^{j}} \frac{\partial V_{t+1}\left(r_{t+1}^{j}, a_{t+1}^{j} ; s_{t+1}\right)}{\partial r_{t+1}^{j}} f(\varepsilon) d \varepsilon .
\end{aligned}
$$

The maximand in is determined by

$$
b_{t}^{j}=\min \left[\max \left(a_{t}^{j}, 0\right), \widehat{b}_{t}^{j}\right] .
$$

If $a_{t}^{j} \geq 0$, the constraint $b_{t}^{j} \leq a_{t}^{j}$ is binding if

$$
\widehat{b}_{t}^{j} \geq a_{t}^{j} .
$$

In this case,

$$
\begin{gathered}
b_{t}^{j}=a_{t}^{j}, \\
\frac{\partial V_{t}\left(s_{t}^{j} ; s_{t}\right)}{\partial r_{t}^{j}}=-i^{d}\left[1-F\left(r_{T}^{j}\right)\right]+\int_{-\infty}^{d_{t}^{j}} \frac{\partial V_{t+1}\left(r_{t+1}^{j}, a_{t+1}^{j} ; s_{t+1}\right)}{\partial r_{t+1}^{j}} f(\varepsilon) d \varepsilon,
\end{gathered}
$$


and

$$
\frac{\partial V_{t}\left(s_{t}^{j} ; s_{t}\right)}{\partial a_{t}^{j}}=i_{t}+\int_{-\infty}^{\infty} \frac{\partial V_{t+1}}{\partial a_{t+1}^{j}} f(\varepsilon) d \varepsilon .
$$

If $a_{T}^{j}<0$, the constraint $b_{T}^{j} \leq 0$ is binding if

$$
\widehat{b}_{t}^{j} \geq 0 \text {. }
$$

In this case,

$$
\begin{gathered}
b_{T}^{j}=0, \\
\frac{\partial V_{t}\left(s_{t}^{j} ; s_{t}\right)}{\partial r_{t}^{j}}=-i^{d}\left[1-F\left(r_{t}^{j}\right)\right]+\int_{-\infty}^{r_{t}^{j}-a_{t}^{j}} \frac{\partial V_{t+1}\left(r_{t+1}^{j}, a_{t+1}^{j} ; s_{t+1}\right)}{\partial r_{t+1}^{j}} f(\varepsilon) d \varepsilon,
\end{gathered}
$$

and

$$
\begin{aligned}
\frac{\partial V_{T-1}}{\partial a_{T-1}^{j}}= & i^{l} F\left(-a_{t}^{j}\right)+i^{d}\left[1-F\left(r_{t}^{j}-a_{t}^{j}\right)\right]-\int_{b_{t}^{j}-a_{t}^{j}}^{r_{t}^{j}+b_{t}^{j}-a_{t}^{j}} \frac{\partial V_{t+1}}{\partial r_{t+1}^{j}} f(\varepsilon) d \varepsilon \\
& +\int_{-\infty}^{\infty} \frac{\partial V_{t+1}}{\partial a_{t_{+}}^{j}} f(\varepsilon) d \varepsilon .
\end{aligned}
$$

\section{References}

[1] Angeloni, I. and E. Bisagni (2002): "Liquidity Effects in the Euro Area" Mimeo, ECB and Univ. California, San Diego.

[2] Bartolini, L., G. Bertola and A. Prati (2000): "Banks' Reserve Management, Transaction Costs, and the Timing of Federal Reserve Intervention" Journal of Banking and Finance 25 (7): 1287-1317.

[3] Bindseil, U. (2000): "Central Bank Liquidity Management: Theory and Euro Area Practice". European Central Bank.

[4] Bindseil, U. and F. Seitz, (2001) "The Supply and Demand for Eurosystem Deposits the First 18 Months" European Central Bank Working Paper 44.

[5] Campbell, J. Y. (1987): "Money Announcements, the Demand for Bank Reserves, and the Behavior of the Federal Funds Rate within the Statement Week" Journal of Money, Credit, and Banking 19 (1): 56-67. 
[6] Deustche Bundesbank (1995): The Monetary Policy of the Bundesbank, October.

[7] Escrivá, J. L. and G. P. Fagan (1996): "Empirical Assessment of Monetary Policy Instruments and Procedures in EU Countries" European Monetary Institute Staff Paper 2.

[8] European Central Bank (1998): The Single Monetary Policy in Stage Three: General Documentation on ECB Monetary Policy Instruments and Procedures, September.

[9] Gaspar, V. G. Pérez Quirós, and J. Sicilia (2001): "The ECB Monetary Policy Strategy and the Money Markets" International Journal of Finance and Economics 6 (4): 325-342.

[10] Hamilton, J. D. (1996): "The Daily Market for Federal Funds" Journal of Political Economy 104 (1): 26-56.

[11] Hartman, P., M. Manna and A. Manzanares (2001): "The Microstructure of the Euro Money Market" Journal of International Money and Finance 20 (6): 895-948.

[12] Nelson, D. B. (1991): "Conditional Heteroskedasticity in Asset Returns: A New Approach" Econometrica 59 (2): 347-370.

[13] Prati, A, L. Bartolini, L and G. Bertola (2002): "The Overnight Interbank Market: Evidence from the G-7 and the Euro Zone" CEPR Discussion Paper 3090.

[14] Spindt, P. A. and J. R. Hoffmeister (1988): "The Micromechanics of the Federal Funds Market: Implications for Day-of-the-Week Effects in Funds Rate Variability" Journal of Financial and Quantitative Analysis 23 (4): 401-415.

[15] Wurtz, F.R. (2003) "A Comprehensive Model on the Euro Overnight Rate" European Central Bank Working Paper 207. 


\section{FIGURE 1}

Spread: overnight rate minus official rate

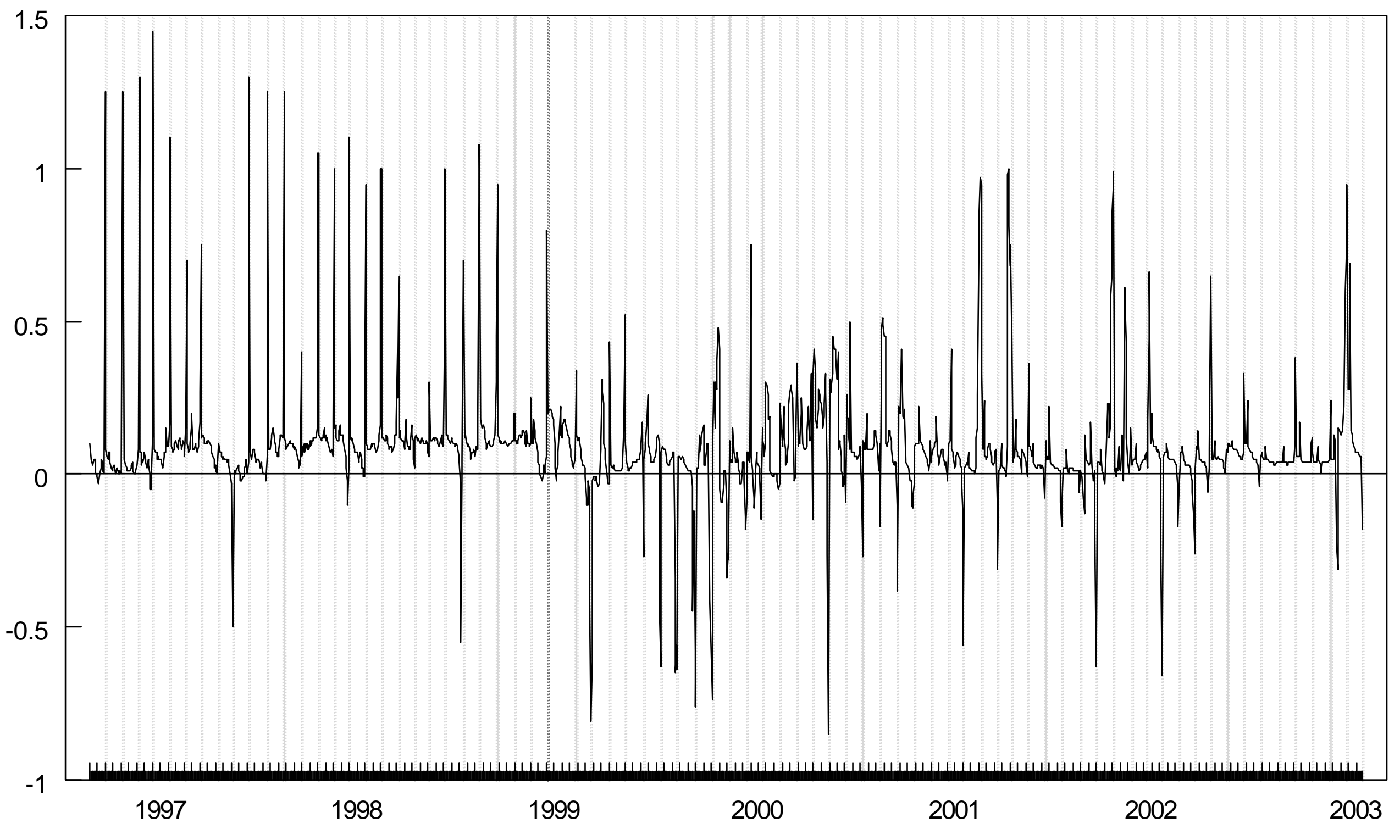

The solid line represents the difference between the overnight rate and the target rate at a daily frequency. The dotted lines are ends of maintenance periods. The sample covers from September 1996 to December 1998 for Germany and from January 1999 to January 2003 for the Euro-Area. 


\section{FIGURE 2 \\ Spread: overnight rate minus official rate}

Sep. 96 - Dec. 98

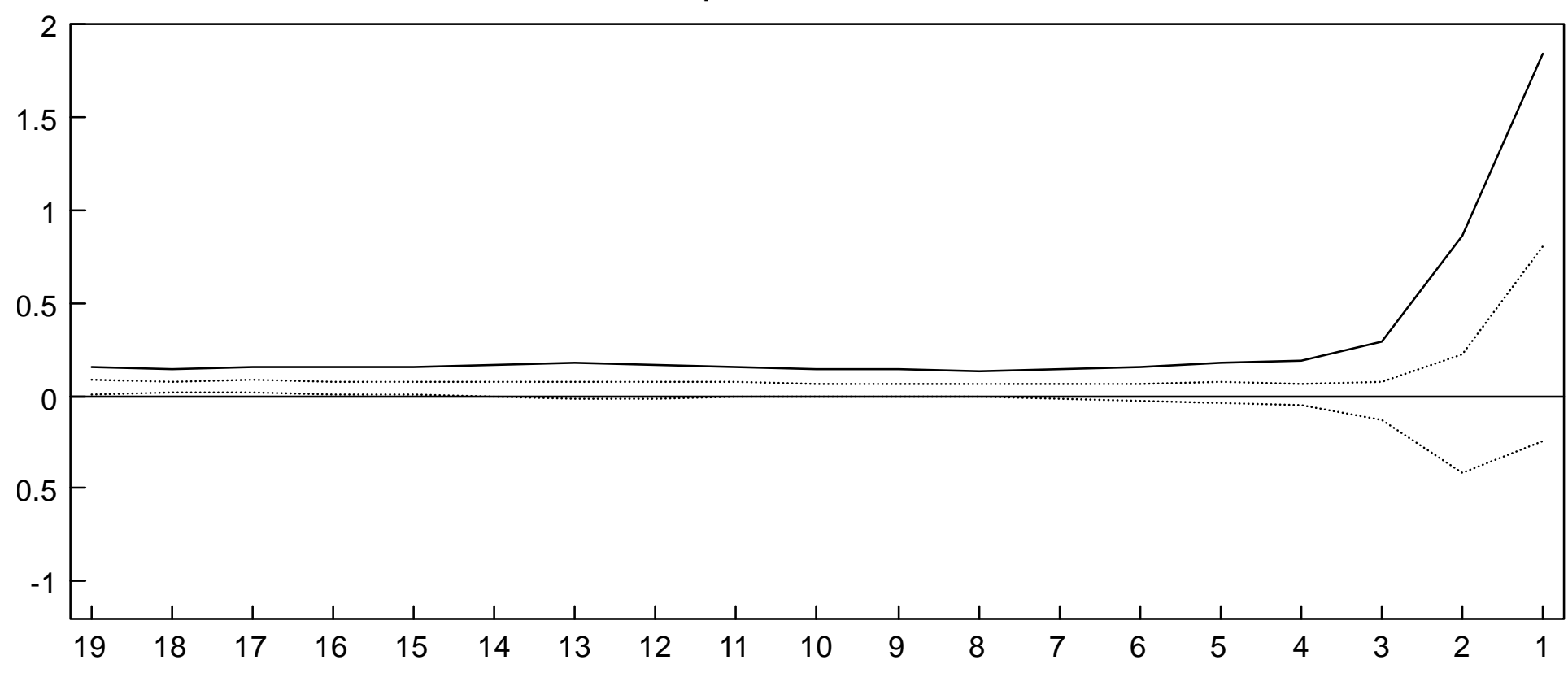

Jan. 99 - Jan. 03



In both figures, the horizontal axis represents the number of days until the next reserve maintenance period. The solid line is the average spread for each day of the maintenance period. The dotted lines form a two-standard deviation band. 